\title{
Relevance of lactate level detection in migrane and fibromyalgia
}

\author{
Patrizia Proia (1), Alessandra Amato (1), Valentina Contrò (1), Alessandra Lo Monaco \\ (1), Jessica Brusa (1), Filippo Brighina (2), Giuseppe Messina (1) \\ 1) Department of Psychology, Educational Science and Human Movement, University \\ of Palermo; (2) Department of Experimental Biomedicine and Clinical Neurosciences \\ (BIONEC), University of Palermo, Italy
}

This article is distributed under the terms of the Creative Commons Attribution Noncommercial License (CC BY-NC 4.0) which permits any noncommercial use, distribution, and reproduction in any medium, provided the original author(s) and source are credited.

\begin{abstract}
The aim of this study was to determine the blood lactate levels in healthy and pathological subjects, particularly with migraine and fibromyalgia. Moreover we investigated the possible correlation between lactate concentration, postural stability and balance disorders; the composition of the groups were: migraine $(n=25$; age $49.7 \pm 12.5)$, fibromyalgia $(n=10$; age $43.7 \pm 21.2)$, control group $(n=16$ age $28.52 \pm 2.4)$. The results showed that patients with fibromyalgia (FG) had higher lactate levels compared to migraine (MG) and control group (CG) (mean \pm sd: $\mathrm{FG}=1.78 \pm 0.9 \mathrm{mmol} / \mathrm{L} ; \mathrm{MG}=1.45 \pm 1 \mathrm{mmol} / \mathrm{L} ; \mathrm{CG}=0,85 \pm 0,07 \mathrm{mmol} / \mathrm{L}$ ). The same situation was highlighted about the sway path length with eyes closed $(\mathrm{FG}=518 \pm 195$ $\mathrm{mm} ; \mathrm{MG}=465 \pm 165 \mathrm{~mm} ; \mathrm{CG}=405 \pm 94,72 \mathrm{~mm})$ and with eyes open $(\mathrm{FG}=430 \pm 220 \mathrm{~mm}$; $\mathrm{MG}=411 \pm 143 \mathrm{~mm} ; \mathrm{CG}=389 \pm 107 \mathrm{~mm}$ ). This can be explained by the fact that energyintensive postural strategies must be used to optimize both static and dynamic coordination, in particular with repeated contractions of tonic oxidative muscle cells responsible for postural control.
\end{abstract}

Key Words: lactate level, fibromyalgia, migraine, postural control.

Eur J Transl Myol 29 (2): 92-96, 2019

Lactate production has often been associated with a certain intensity of exercise however the response to different types of physical exercise depends on many facts including genetics. ${ }^{1}$ To date lactic acid is considered as a product of both muscle metabolism and central nervous system. Numerous and recent studies show that this metabolite is involved in various cellular functions of body such as L-lactate as an intercellular signaling molecule involved in synaptic plasticity but also sustain neuronal function and viability like a Metabolite and a Regulator in the Central Nervous System. ${ }^{2}$ Changes in lactate concentration are related to various physiological and pathological conditions for example Migraine (MG) and Fibromyalgia (FM). ${ }^{3,4}$ Migraine is a chronic neurological disorder characterized by recurrent monolateral, moderate-tosevere headaches, often in association with a series of symptoms of the autonomic nervous system and characterized by an increase in lactate concentrations. Hypoxia has long been known to have the potential to trigger migraine attacks, ${ }^{5}$ and is associated with an increase in brain lactate ${ }^{6}$ and this increase in lactate in association with hypoxia has been shown to be related to migraineurs. ${ }^{7,8}$ It is not clear how the increase in lactate is mediated, either through mitochondrial dysfunction or other mechanisms. Lactate brain responses can be mediated through some ion channels particularly acid-sensing ion channel 3 (ASIC) sensitive to $\mathrm{pH}$ changes. This lactate increase in brain in response to a recognized migraine trigger further suggests that ASICs may be involved in mediating lactate response and therefore in migraine mediation. ${ }^{9}$ The second pathology we take into consideration is Fibromyalgia (FM): a chronic syndrome characterized by generalized muscle pain, joint rigidity intense fatigue and postural instability, ${ }^{10}$ probably due to an abnormal amplification of pain signals in the spinal cord. Different strategies can be used to mitigate the chronic pain of this pathology, among the different hypotheses there is also that of myofunctional therapy which, in general in other pathologies, is shown to be an effective therapeutic strategy with regards to the treatment of muscle pain and hypertonia. ${ }^{11,12}$ 
Fibromyalgia is also characterized by an increase in lactate levels. Several studies show how higher lactate and pyruvate in muscle were found in the painful muscle. ${ }^{13}$ Increased lactate concentration can indicate tissue hypoxia according to experimental and clinical studies; ${ }^{13,14}$ but there are several hypotheses that explain this phenomenon. It is not clear if fibromyalgia causes lactate increasing or on the contrary increased lactate (caused by several factors) can predispose to develop fibromyalgia for example through directly altering the nociceptors activity or acting on other channels. Wasserman interpreted accumulation of lactate as a consequence of the end product of anaerobic glycolysis; ${ }^{15}$ other study shows that fibromyalgic subjects had significantly increased muscle lactate, but no significant difference in blood flow. ${ }^{16}$ This would mean that increased levels of these metabolites cannot be completely explained by insufficient oxygen supply and anaerobic conditions. Lactate is also produced and consumed during adequate oxygen provision. ${ }^{16,17}$ Another hypothesis considers the role of adrenaline to lead an increase in lactate release and lipolysis in the muscle in condition of normal blood flow and tissue oxygenation. It has been discussed whether FM is characterized by a derangement of the sympathetic nervous system. ${ }^{16-18}$ Disturbances in lactate shuttles mechanisms and mitochondrial function is another explanation for the increase in muscle lactate. ${ }^{19,20}$ Lactate is involved in peripheral nociception, and it appears (together with ATP) to facilitate the response of ASIC (neuronal voltage-insensitive sodium channels activated by extracellular protons permeable to $\mathrm{Na}^{+}$) following exposure to a low $\mathrm{pH}^{21,22}$ The aim of this study was to determine the relationships of migraine and fibromyalgia and lactate levels in the blood, focusing in particular on correlations with postural stability and balance disorders.

\section{Materials and Methods}

\section{Subjects}

Sixty subjects were enrolled in our study, twenty-five healthy subjects for the control group (CG) (age 28.52 \pm 2.4 ; height $169 \pm 10 \mathrm{~cm}$; weight $65,64 \pm 15,32 \mathrm{~kg}$ ) and thirty-five pathological subjects. Based on the diagnosis previously made and certified by medical specialists, the division of subjects was performed into two groups: 1) patients with fibromyalgia (FG) $(n=10$; age $43.7 \pm 21.2$; height $158 \pm 5.65 \mathrm{~cm}$; weight $70 \pm 28.9$ $\mathrm{kg}) ; 2)$ patients with migraine $(\mathrm{MG})(\mathrm{n}=25$; age $49.7 \pm$ 12.5; height $164.9 \pm 6.62 \mathrm{~cm}$; weight $68.6 \pm 16.9 \mathrm{~kg}$ ).

\section{Study design}

Participants provided informed consent before the study commenced and all procedures received local ethics committee approval. Assessments included personal data and anthropometric measurements and analysis with a stabilometric analysis (Sensor Medica Maxi 50x60 Software by Freestep), the subjects did not perform any physical activity during the day before stabilometry. The postural analysis of the subjects was carried out also in different days and day times to meet the needs of the participants, this was possible because it was demonstrated, ${ }^{23}$ that the day time in which the postural analysis is carried out does not significantly influence the result. The Stabilometric Platform is an evolved evaluation tool consisting of a platform, in which the patient must rest his feet remaining in an upright position, connected to a computer, records postural oscillations in space and time and check if these are consistent with the oscillation frequency typical of the human body, ${ }^{24}$ in order to evaluate balance and plantar support, performed with open eyes and with closed eyes. The stabilometric assessments investigated the "ellipse surface" (dispersion of postural oscillations: coordinates of the Pressure Center along the frontal (X; right-left; X-mean) and sagittal (Y; forward-backward; Y-mean) planes, ${ }^{21}$ expressed in $\mathrm{cm}^{2}$, both with eyes open and closed and "sway path length" (length of the sway of the Pressure Center) ${ }^{24}$ in all subjects, comparing these data with the postural analysis data of a cohort of healthy people; ${ }^{25}$ furthermore, basal blood lactate was assessed using a portable lactacidometer (Accutrend Plus System Roche) the sample was taken in the fingertip. The lactate was taken about two hours after lunch and the subject had not carried out physical activity during the morning or immediately before.

\section{Statistical analysis}

Statistical analysis was performed using Student $t$ test for unpaired data. Pearson correlation test was used when appropriate. An alpha value <0.05 was considered statistically significant. The SPSS statistical package version 16.0 for Windows (SPSS, Inc., Chicago, IL, USA) was used to perform all statistical evaluations.

\section{Results}

The analysis of results showed a $p$ value not statistical significant when comparing the ellipse surface (FG: $212,97 \pm 482,4 \mathrm{~mm}^{2} ; \mathrm{MG}: 172,63 \pm 287,3 \mathrm{~mm}^{2} ; p>$ 0.05 ) and the sway path length (FG: $430,65 \pm 221 \mathrm{~mm}$; MG: $411,19 \pm 144 \mathrm{~mm} ; p>0.05)$ in FG and MG groups with eyes open. There is not a statistical significant difference between the ellipse surface (FG: 523,26 \pm 990,3 $\mathrm{mm}^{2}$. MG: $\left.166,12 \pm 349 \mathrm{~mm}^{2} ; p>0.05\right)$ and sway path length (FG: 518,5 \pm 195,2 mm; MG: 465,32 \pm 165,6 mm $p>0.05$ ) between FG and MG with eyes closed too. Regarding the comparison with the control group and both pathological groups (FG and $\mathrm{MG}$ ), statistical significant difference was detected between the ellipse surface between CG $\left(38,7 \pm 41,9 \mathrm{~mm}^{2}\right)$ and FG $\left(523,3 \pm 990 \mathrm{~mm}^{2}\right)$ with eyes closed $(p=0,02)$ and in the sway path length with eyes closed (CG: 405,34 \pm 94,7 mm; FG: 518,5 \pm 195,2 mm; $p=0,03$ ), (Table 1, Table 2). In addition there was a statistically significant 


\section{Lactate level in migrane and fibromyalgia}

Eur J Transl Myol 29 (2): 92-96, 2019

\begin{tabular}{|cc|c|c|c|}
\hline \multicolumn{6}{|c|}{ Table 1. Different sway path length value between groups (mm) } \\
\hline Group & O. E & P value & C. E & P value \\
\hline FG & $430.65 \pm 221$ & & $518.46 \pm 195$ & \\
VS & P $>0.05$ & $465.32 \pm 150$ & P $>0.05$ \\
MG & $411.19 \pm 144$ & & $518.46 \pm 195$ & \\
\hline FG & $430.65 \pm 221$ & & $\mathrm{P}>0.05$ & \\
VS & & $405.34 \pm 94.7$ & \\
CG & $389.33 \pm 107,4$ & & $405.33 \pm 94,7$ & $\mathrm{P}>0.05$ \\
\hline CG & $389.33 \pm 107,4$ & $\mathrm{P}>0.05$ & $465.32 \pm 165$ & \\
VS & $411.19 \pm 144$ & & & \\
MG & & & \\
\hline
\end{tabular}

different in lactate concentrations between both pathological groups (mean \pm sd: $\mathrm{FG}=1.78 \pm 0.9$ $\mathrm{mmol} / \mathrm{L} ; \mathrm{MG}=1.45 \pm 1 \mathrm{mmol} / \mathrm{L} ; \mathrm{P}=0,00)$ and between pathological groups and control group: (mean $\pm \mathrm{sd}: \mathrm{FG}=1.78 \pm 0.9 \mathrm{mmol} / \mathrm{L} ; \mathrm{CG}=0,85 \pm 0,07$ $\mathrm{mmol} / \mathrm{L} ; \mathrm{P}=0,00 . \mathrm{MG}=1.45 \pm 1 \mathrm{mmol} / \mathrm{L} ; \mathrm{CG}=0,85 \pm$ 0,07 mmol/L; $\mathrm{P}=0,00)$, (Table 3). Performed a Pearson's analysis among the above mentioned stabilometric results and basal lactate levels obtained in all groups, we pulled out a different situation. As a matter of fact in FM group, but not in MG, there was a moderate negative correlation between the sway path lengthand lactate levels both with eyes closed ( $\mathrm{r}=$ $0.53)$ and with eyes open $(r=-0.43)$ (Figure 1).

\section{Discussion}

This study investigated the possible correlation between some stabilometric parameters and lactate concentration in our three different groups. We found some differences in lactic acid metabolism both in FM and in $\mathrm{M}$ group: patients with fibromyalgia had higher lactate levels compared to MG and CG (mean \pm sd: FG $=1.78 \pm 0.9 \mathrm{mmol} / \mathrm{L} ; \mathrm{MG}=1.45 \pm 1 \mathrm{mmol} / \mathrm{L} ; \mathrm{CG}=0,85$ $\pm 0,07 \mathrm{mmol} / \mathrm{L})$. The same situation was highlighted either to concern the sway path length with eyes closed (FG $518 \pm 195$ mm; MG $465 \pm 165$ mm; CG $405 \pm$ $94,72 \mathrm{~mm}$ ) and with eyes open (FG $430 \pm 220 \mathrm{~mm}$; MG $411 \pm 143 \mathrm{~mm}$; CG $389 \pm 107 \mathrm{~mm})$. We can explain this since FG, in order to optimize both static and dynamic coordination, must use more complex and energy-intensive postural strategies in particular with

\begin{tabular}{|cc|c|c|c|}
\hline \multicolumn{5}{|c|}{ Table 2. Different Ellipse surface value between groups $\left(\mathrm{mm}^{2}\right)$} \\
\hline Group & O. E & P value & C. E & P value \\
\hline FG & $212.97 \pm 482$ & & $523.26 \pm 99$ & \\
VS & P $>0.05$ & $166.12 \pm 35$ & \\
MG & $172.63 \pm 287$ & & 5.05 \\
\hline FG & $212.97 \pm 482$ & $\mathrm{P}>0.05$ & $523.26 \pm 990$ & $\mathrm{P}<0.05$ \\
VS & $72.98 \pm 74$ & & $38.67 \pm 41$ & \\
CG & $72.98 \pm 74$ & & $38.67 \pm 41$ & \\
\hline CG & & & \\
VS & & & \\
MG & $172.63 \pm 287$ & & $166.12 \pm 35$ & \\
\hline
\end{tabular}

\begin{tabular}{|c|c|c|}
\hline \multicolumn{3}{|c|}{ Table 3. Different Lactate value between groups ( $(\mathrm{mmol} / \mathrm{L}$ ) } \\
\hline Group & & $P$ value \\
\hline $\begin{array}{l}\text { FG } \\
\text { VS } \\
\text { MG }\end{array}$ & $\begin{array}{c}1.78 \pm 0,9 \\
1.45 \pm 1\end{array}$ & $\mathrm{P}<0.05$ \\
\hline $\begin{array}{l}\text { FG } \\
\text { VS } \\
\text { CG }\end{array}$ & $\begin{array}{l}1.78 \pm 0,9 \\
0.85 \pm 0,7\end{array}$ & $\mathrm{P}<0.05$ \\
\hline $\begin{array}{l}\text { CG } \\
\text { VS } \\
\text { MG }\end{array}$ & $\begin{array}{c}0.85 \pm 0,7 \\
1.45 \pm 1\end{array}$ & $\mathrm{P}<0.05$ \\
\hline
\end{tabular}

repeated contractions of tonic oxidative muscle cells responsible for postural control. These cells, unlike glycolytic muscle cells, have a greater number of mitochondria and they are more vascularized; as a consequence, they mainly exploit aerobic metabolism. The increase in lactate production may be explained because of excessive work of these cells, even though the highest level of lactate, especially in FG, have been shown in more stable subjects, affirming a negative correlation between lactate production and instability ( $r$ $=-0,43$ eyes open; $r=-0,53$ eyes closed). This anomalous result could be explained with different hypotheses: fibromyalgia involves the central and peripheral nervous system, alters the conduction of the nervous signals and also signals starting from esteroceptors and proprioceptors that activate tonic muscle fibres in case of loss of balance: if receptors do not perform their function, tonic muscle fibres can not

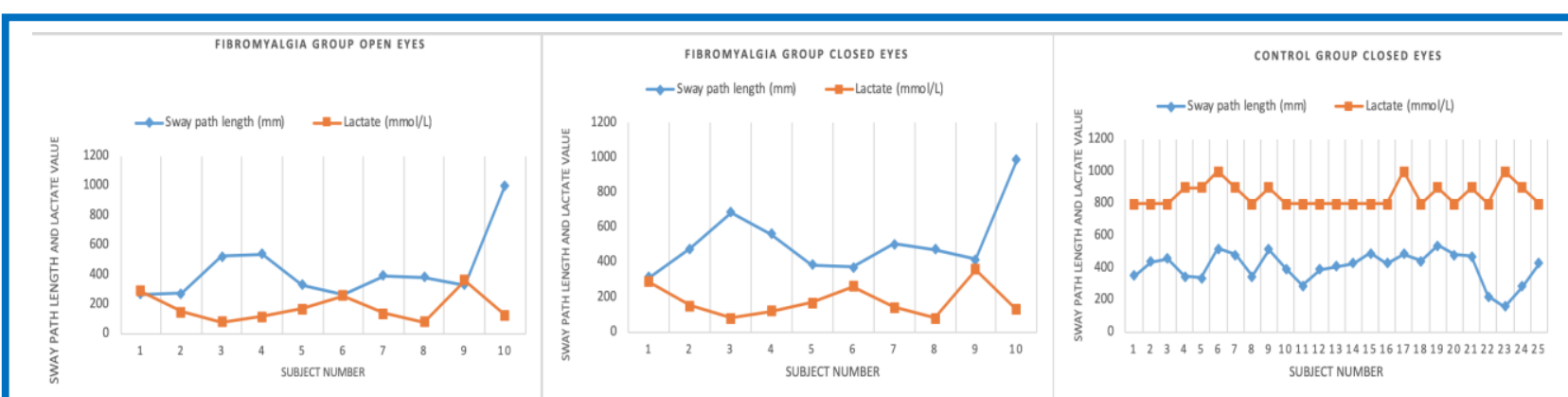

Fig 1. Correlation between lactate $(\mathrm{mmol} / \mathrm{L})$ and sway path length $(\mathrm{mm})$ in $\mathrm{FG}$ with open eyes $(\mathrm{b})$; Correlation between lactate $(\mathrm{mmol} / \mathrm{L})$ and sway path length $(\mathrm{mm})$ in $F G$ with closed eyes $(a) ; C o r r e l a t i o n ~ b e t w e e n ~ l a c t a t e ~(m m o l / L)$ and sway path length ( $\mathrm{mm}$ ) in $C G$ with closed eyes (c). 
contract at their best, so they do not produce lactate over time. Another hypothesis may consider another symptom fibromyalgia-related, that is hypervascularization of some muscular districts, in particular of the tender points. ${ }^{24,26}$ This would increase the oxygen availability in muscle fibres and it would leads to a prevalent use of aerobic metabolism with low lactate production.

In conclusion, despite the hypotheses previously discussed, there are many evidences that show a significantly greater instability in fibromyalgic subjects as well as higher lactate levels at rest compare with subjects with migraine and non-pathological subjects. However, the loss of stability, analysed by stabilometry (particular the measurement of the sway path length and ellipse surface) and concentration of lactate are negatively correlated. Therefore further studies will be necessary to better understand the meaning of this strong inverse correlation and consequently how lactate influences subject stability.

\section{List of acronyms}

ASIC - acid-sensing ion channel 3

$\mathrm{CG}$ - control group

FG - fibromyalgia

$\mathrm{MG}$ - migraine

\section{Authors contributions}

All named authors played a substantial role in the conception and/or study design, data acquisition and/or analysis, as well as drafting of the manuscript, approval of the final version to be published, and agree the accountability for all aspects of accuracy and integrity of the work.

\section{Acknowledgments}

None.

Funding No funding was obtained for this research project.

\section{Conflict of Interest}

The authors declare they have no financial, personal, or other conflicts of interest.

\section{Ethical Publication Statement}

We confirm that we have read the Journal's position on issues involved in ethical publication and affirm that this report is consistent with those guidelines.

\section{Corresponding Author}

Giuseppe Messina, Department of Psychology, Educational Science and Human Movement, Sport and Exercise Sciences Research Unit, University of Palermo, Italy. Email: giuseppe.messina17@unipa.it

\section{E-mails of co-authors}

Patrizia Proia: patrizia.proia@unipa.it Alessandra Amato: amale94@hotmail.it
Valentina Contrò: valecontro@gmail.com

Alessandra Lo Monaco: alelo89@live.it

Jessica Brusa: brusajessica@gmail.com

Filippo Brighina: filippo.brighina@unipa.it

\section{References}

1. Contrò V, Schiera G, Abbruzzo A, et al. An innovative way to highlight the power of each polymorphism on elite athletes phenotype expression. Eur J Transl Myol 2018;28(1):7186. doi:10.4081/ejtm.2018.7186

2. Proia P, Di Liegro CM, Schiera G, et al. Lactate as a Metabolite and a Regulator in the Central Nervous System. Int J Mol Sci 2016;17:1450.

3. De Sá Ribeiro GA1, Scola RH2, Piovesan EJ3, et al. The importance of lactic acid in migraines and fibromyalgia. Rev Bras Reumatol 2015;55:471-6.

4. Amery WK. Brain hypoxia in migraine: pathophysiologic and therapeutic implications. J Cereb Blood Flow Metab 1982;2(Suppl):S62-5.

5. Amery WK. Brain hypoxia: the turning-point in the genesis of the migraine attack? Cephalalgia 1982;2:83-109.

6. Edden RA, Harris AD, Murphy K, et al. Edited MRS is sensitive to changes in lactate concentration during inspiratory hypoxia. J Magn Reson Imaging: JMRI 2010;32:320-5.

7. Watanabe H, Kuwabara T, Ohkubo M, et al. Elevation of cerebral lactate detected by localized $1 \mathrm{H}$-magnetic resonance spectroscopy in migraine during the interictal period. Neurology 1996;47:1093-5.

8. Sandor PS, Dydak U, Schoenen J, et al. MRspectroscopic imaging during visual stimulation in subgroups of migraine with aura. Cephalalgia 2005;25:507-18.

9. Karsan N, Gonzales EB, Dussor G. Targeted Acid-Sensing Ion Channel Therapies for Migraine. Neurotherapeutics 2018;15:402-14.

10. Muto LH, Sauer JF, Yuan SL, et al. Postural control and balance self-efficacy in women with fibromyalgia: are there differences? Eur J Phys Rehabil Med 2015;51:149-54.

11. Messina G, Martines F, Thomas E, et al. Treatment of chronic pain associated with bruxism through Myofunctional therapy. Eur J Transl Myol 2017;27(3):6759. doi: 10.4081/ ejtm.2017.6759. eCollection 2017 Jun 27.

12. Carraro U. Exciting perspectives for Translational Myology in the Abstracts of the 2018Spring PaduaMuscleDays: Giovanni Salviati Memorial Chapter IV - Abstracts of March 17, 2018. Eur J Transl Myol 2018;28(1):7366. Published 2018 Feb 20. doi:10.4081/ejtm.2018.7366.

13. Setala LP, Korvenoja EM, Harma MA, et al. Glucose, lactate, and pyruvate response in an experimental model of microvascular flap 


\section{Lactate level in migrane and fibromyalgia}

Eur J Transl Myol 29 (2): 92-96, 2019

ischemia and reperfusion: a microdialysis study. Microsurgery 2004;24:223-31.

14. Tozzi M, Muscianisi E, Piffaretti G, et al. Microdialysis assessment of peripheral metabolism in critical limb ischemia after endovascular revascularization. Ann Surg Innov Res 2009; 3:17.

15. Wasserman K. The anaerobic threshold measurement to evaluate exercise performance. Am Rev Respir Dis 1984;129:S35-S40.

16. Philip A, Macdonald AL, Watt PW. Lactate-a signal coordinating cell and systemic function. Exp Biol 2005;208: 4561-75.

17. Robergs RA, Ghiasvand F, Parker D. Biochemistry of exercise-induced metabolic acidosis. Am J Physiol Regul Integr Comp Physiol 2004;287:R502-16.

18. Elvin A, Siosteen AK, Nilsson A, et al. Decreased muscle blood flow in fibromyalgia patients during standardised muscle exercise: a contrast media enhanced colour Doppler study. Eur J Pain 2006;10:137-44.

19. Lanza IR, Nair KS. Muscle mitochondrial changes with aging and exercise. Am J Clin Nutr 2009;89:467S-71.

20. Lanza IR, Short DK, Short KR, et al. Endurance exercise as a countermeasure for aging. Diabetes 2008;57:2933-42.
21. Birdsong WT, Fierro L, Williams FG, et al. Sensing muscle ischemia: coincident detection of acid and ATP via interplay of two ion channels. Neuron 2010;68:739-49.

22. Deval E, Gasull X, Noel J, et al. Acid-sensing ion channels (ASICs): pharmacology and implication in pain. Pharmacol Ther 2010;128:549-58.

23. Russo L, D'Eramo U, Padulo J, et al. Day-time effect on postural stability in young sportsmen. Muscles Ligaments Tendons J 2015;5(1):38-42.

24. Scoppa F, Capra R, Gallamini M, et al. Clinical stabilometry standardization: basic definitionsacquisition interval-sampling frequency. Gait Posture 2013;37:290-2.

25. Patti A, Bianco A, Şahin N, et al Postural control and balance in a cohort of healthy people living in Europe: An observational study. Medicine 2018. 97(52):e13835.

26. Scolnik M, Vasta B, Hart DJ, et al. Symptoms of Raynaud's phenomenon (RP) in fibromyalgia syndrome are similar to those reported in primary RP despite differences in objective assessment of digital microvascular function and morphology. Rheumatol Int 2016;36:1371-77.

Submissions: April, 05, 2019

Revision received: April 16, 2019

Acceptance: April 17, 2019 